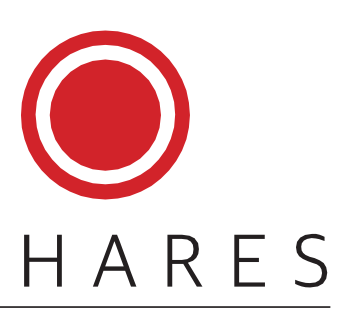

REVISTA DO DEPARTAMENTO DE EDUCAC̨̈̈O - UNIFESP

\title{
PEDAGOGIA(S) DA INFÂNCIA, PENSAMENTO FREIRIANO E A BUSCA DE UM PROJETO EDUCATIVO DEMOCRÁTICO
}

\author{
PEDAGOGÍA(S) INFANTIL, PENSAMIENTO FREIRIANO Y LA BÚSQUEDA \\ DE UN PROYECTO EDUCATIVO DEMOCRÁTICO
}

\author{
CHILDHOOD PEDAGOGIES, THOUGHT OF PAULO FREIRE AND THE \\ SEARCH FOR A DEMOCRATIC EDUCATIONAL PROJECT
}

\author{
Sariane da Silva Pecoits \\ Universidade Federal do Rio Grande do Sul - UFGRS \\ sariane.pecoits@gmail.com \\ Claines Kremer \\ Universidade Federal do Rio Grande do Sul -UFRGS \\ claineskremer@gmail.com \\ Maria Carmen Silveira Barbosa \\ Universidade Federal do Rio Grande do Sul -UFRGS \\ licabarbosa@ufrgr.br
}

\begin{abstract}
Resumo Este ensaio discute as concepções educativas das Pedagogias da Infância na Educação Infantil (EI) e tem como objetivo articular o pensamento freiriano a essa perspectiva na busca de sustentação de projeto educativo democrático para a primeira infância. A fundamentação teórica que orienta este trabalho tem como base autores da Educação Infantil e os pressupostos teóricos elaborados pelo educador Paulo Freire. $\mathrm{O}$ estudo tem como indicativo que as críticas tecidas às Pedagogias da Infância em especial a sugestão de fragilidade pedagógica a ela conferida no que diz respeito à centralidade das crianças e organização do trabalho docente, podem ser reexaminadas a partir desse diálogo. Depreende-se que as concepções de educação e democracia freirianas podem ser valiosos aportes na discussão de processos educativos na El para sustentação da garantia da participação das crianças em seu processo de aprendizagem.
\end{abstract}

Palavras-chave: Pedagogias da Infância. Pensamento Freiriano. Educação. Democracia.

Resumen: Este ensayo discute las concepciones educativas de las pedagogias da infância en la Educación Infantil y tiene como objetivo articular el pensamiento freiriano a esa perspectiva en la búsqueda de apoyo de proyecto educativo democrático para la primera infancia. La fundamentación teórica que orienta ese ensayo tiene como base autores de la Educación Infantil y los presupuestos teóricos elaborados por el educador Paulo Freire. El estudio tiene como indicativo que las críticas tejidas a las pedagogias de la infância, en especial la sugerencia de fragilidade pedagógica a ella conferida con respecto a la centralidad de los niños y organización del trabajo docente, pueden ser reexaminadas a partir de este diálogo. Se infiere que las concepciones de Educación y democracia freirianas pueden ser valiosas contribuciones en la discución de procesos educativos en la Educación Infantil para apoyo de la garantía de la participación de los niños en su proceso de aprendizaje. 
Palabras clave: Pedagogías de la infancia. Pensamiento Freiriano. Educación. Democracia.

\begin{abstract}
This essay addresses the educational concepts of pedagogies of childhood in Early Childhood Education and aims to articulate Paulo Freire's thoughts on this perspective in order to support a democratic educational project for early childhood. The theoretical foundation that guides this essay is founded on authors of Early Childhood Education and the theoretical assumptions developed by the educator and philosopher Paulo Freire. The study indicates that the criticism of the pedagogeis of childhood, especially the suggestion of pedagogical fragility attributed to it regarding the central role of children and the organization of teaching work, can be reviewed here. It appears that Paulo Freire's concepts of education and democracy can be valuable contributions to the discussion of educational processes in Early Childhood Education to support the guarantee of children's participation in their learning process.
\end{abstract}

Keywords: Childhood pedagogies. Thought of Paulo Freire. Education. Democracy.

\title{
Introdução
}

O atendimento à primeira infância é entendido hoje como um dos principais meios de garantia dos direitos humanos sociais (MACINAI, 2006; MACINAI, 2013; BRASIL, 2016). No Brasil, o tema entra na agenda política governamental a partir da promulgação da Constituição (1988) e, posteriormente e já especificamente no que se refere à Educação, da aprovação da LDB/96, que garantem às crianças de zero a seis anos o atendimento em creches e pré-escolas. Nesses dois documentos, a primeira infância é referenciada como um tempo de cuidado e de educação, ou seja, é essa compreensão que deve orientar as práticas da Educação Infantil, caracterizadas como ações de cuidar e educar - de forma integrada - dos bebês e das crianças pequenas. Na compreensão de que a Escola de Educação Infantil - e o que nela ocorre - desempenha um importante papel no desenvolvimento de ações que garantam e promovam os direitos das crianças, também a temática do currículo dessa etapa da Educação Básica torna-se objeto de debates e discussões nas últimas décadas.

As DCNEI (2009), com bastante clareza, e a BNCC (2017), no histórico de sua construção, apresentam definições e princípios que têm como pressupostos: o entendimento da criança como sujeito histórico e de direitos; o currículo como conjunto de práticas que articulam as experiências e os saberes das crianças ao patrimônio cultural, artístico, ambiental, científico e tecnológico na promoção do desenvolvimento integral dos bebês e das crianças pequenas; e o respeito aos princípios éticos (da autonomia, da responsabilidade, da solidariedade e do respeito ao bem comum, ao meio ambiente e às diferentes culturas, identidades e singularidades), estéticos (da sensibilidade, da criatividade, da ludicidade e da liberdade de expressão nas diferentes manifestações artísticas e culturais) e políticos (dos 
direitos de cidadania, do exercício da criticidade e do respeito à ordem democrática). Podese afirmar, portanto, que do ponto de vista dos territórios em disputa (ARROYO, 2013) no campo das discussões curriculares, tais documentos estão em consonância com os pressupostos das Pedagogias da Infância1.

A elaboração teórica do conceito de Pedagogia da Infância inicia-se no Brasil com as pesquisas das pedagogas Ana Lúcia Goulart Faria (1993) e Eloísa Acires Candal Rocha (1999), a partir de dois estudos em interlocução com os estudos sociais da infância. Neles as autoras indicaram a importância e a necessidade da construção de uma pedagogia que fosse pensada especificamente para as crianças de zero a seis anos de idade em instituições educativas. É a partir da construção do conceito de Pedagogia da Infância que Rocha (1999) apresenta uma diferenciação importante entre a Educação Infantil e os Anos Iniciais do Ensino Fundamental, enfatizando que são etapas que se diferenciam de forma significativa devido à função social de uma e da outra. Para a autora, os Anos Iniciais são o lócus para a aquisição de conhecimentos básicos determinados por um currículo e a Educação Infantil é um espaço de vida coletiva no qual a finalidade é educar e cuidar, complementando a educação das famílias (ROCHA, 1999).

Assim, diferenciando-se das pedagogias centradas na criança - nascidas a partir do movimento da Escola Nova e que faziam uma crítica à pedagogia tradicional a partir dos conhecimentos do campo da biologia e da psicologia evolutiva - as Pedagogias da Infância "constitui-se de um conjunto de fundamentos e indicações de ação pedagógica que tem como referência as crianças e as múltiplas concepções de infância em diferentes espaços educacionais" (BARBOSA, 2010, s/p), tendo como premissa a compreensão de que "toda e qualquer ação educativa exige considerar as crianças e os contextos socioculturais que definem sua infância" (BARBOSA, 2010, s/p). Essa perspectiva pedagógica, ao tomar como base de sua concepção o entendimento de criança como sujeito histórico e de direitos, nos situa em um determinado campo conceitual e nos impõe a declaração de:

[...] indicativos pedagógicos que possibilitem às crianças a experiência da infância de forma a tomar parte em projetos educacionais fundados na democracia, na diversidade, na participação social, a partir de práticas educativas que privilegiem as relações sociais entre todos os segmentos envolvidos (crianças, familiares e educadores) (BARBOSA, 2010, s/p).

\footnotetext{
${ }^{1}$ Ao longo do texto referimos Pedagogia da Infância quando estivermos mencionando o conceito elaborado por ROCHA (1999) e Pedagogia(s) da Infância ao abordarmos o conceito a partir de BARBOSA (2010; 2014), que não opõe a concepção de Pedagogia(s) da Infância aos escola-novistas e sim a situa e a atualiza.
} 
Pode-se afirmar, a partir de Rocha (1999;2013); Oliveira-Formosinho (2007); Barbosa (2010; 2014); e Rocha, Lessa e Buss-Simão (2016), que as Pedagogias da Infância: (i) contrapõem-se às pedagogias transmissivas e às pedagogias espontaneístas do século XX, que tomam as crianças como abstratas e universais; (ii) entendem que as aprendizagens são consequências das relações que as crianças estabelecem com a realidade social; (iii) apontam para a necessidade de uma pedagogia própria para as crianças pequenas e que as considere sujeitos concretos e reais, pertencentes a diferentes contextos sociais e culturais; (iv) compreendem uma dimensão praxiológica - a prática é fruto da reflexão crítica sobre ela própria, dando contorno para uma ação educativa orientada; (v) envolvem um compromisso com os direitos das crianças em relação aos projetos educativos voltados para elas; e (vi) entendem a criança como coprodutora de cultura e detentora de conhecimentos.

No entanto, passadas mais de duas décadas desde a elaboração do conceito de Pedagogia da Infância no Brasil, os indicativos pedagógicos dos quais esta prescinde parecem não ter ultrapassado a barreira de serem uma declaração de princípios. Em outras palavras, precisam ainda serem traduzidos "em modos de fazer inteligíveis, que possam ser apropriados por educadores reais - e não apenas por alguns profissionais excepcionais e adotados nas instituições que temos" (CAMPOS, 2012, p. 19).

Com isto, Campos (2012) afirma que essa pedagogia que proporciona verdadeiramente o respeito à criança ainda está sendo edificada em nosso território e aponta três condições que dificultam essa construção. A primeira delas diz respeito à subordinação da Educação Infantil à etapa do Ensino Fundamental, sinalizando que a pré-escola permanece tendo como referência - ainda que seja na busca por diferenciação — os Anos Iniciais e suas práticas, especialmente para atender demandas de preparação para alfabetização. Em segundo lugar, a autora refere ao impacto que a globalização da economia e um cenário mundial cada vez mais competitivo reflete nas políticas educacionais, afirmando que, se anteriormente a Educação Infantil estava um pouco protegida desse interesse, a sua expansão e visibilidade nos últimos tempos provocou o interesse do mercado financeiro, passando a receber um "tratamento de cunho mais tecnocrático por parte de quem toma decisões na gestão pública" (CAMPOS, 2012, p. 17). A terceira dificuldade apontada pela autora para a efetivação de uma Pedagogia da Infância tem a ver com a relação que se estabelece entre fracasso escolar e o compromisso da escola com as aprendizagens das crianças. A autora aponta que o fato de termos ainda índices altos de analfabetismo, de evasão, de desinteresse dos jovens pela escola e de tantas deficiências de aprendizagem daqueles que permanecem: 
[...] são questões relevantes a serem consideradas para superar nosso alto grau de desigualdade social, assim como para ampliar e aprofundar nossa incipiente democracia; essas questões não podem ser simplesmente descartadas como algo natural ou enquanto problemas que só deveriam preocupar os educadores a partir do ensino fundamental (CAMPOS, 2012, p. 17).

Campos (2012) alerta para o fato de que esse contexto de desigualdade social e de necessidade de aprimoramento da democracia questiona e desafia a Pedagogia da Infância que ainda está em construção, bem como a imagem de criança pequena que essa deseja propagar. A autora provoca ainda uma reflexão importante ao afirmar que "os diques e muros que muitos querem erigir para supostamente proteger a educação infantil dessa realidade conflituosa vêm se revelando bastante porosos" (CAMPOS, 2012, p. 18). Com essa provocação, pensamos que a autora introduz a ideia de que a Educação Infantil não é, e não deve ser, uma etapa da Educação Básica em descontinuidade com as etapas seguintes; que o compromisso com a aprendizagem das crianças por parte dos professores/escola deve ser estabelecido desde seu ingresso na Educação Infantil e que esse ainda é um tema a ser explorado no âmbito da proposição de uma Pedagogia da Infância tal como a conhecemos a partir de Faria (1993) e Rocha (1999).

Para a superação dessas três dificuldades apontadas, a autora inicia a discussão anunciando que é preciso assumir que, apesar da mudança nos discursos pedagógicos, "as práticas adotadas na maioria das creches e pré-escolas conferem muito pouco espaço ao protagonismo infantil” (CAMPOS, 2012, p. 18). Avançando ainda mais nessa crítica, a autora afirma que essas práticas parecem ainda "reproduzir as velhas estruturas de uma pedagogia arcaica, enraizada em tradições até mesmo anteriores àquelas denunciadas por pedagogos reconhecidos de séculos atrás" (p. 18). Campos discorre também sobre as mudanças nas condições que ainda hoje qualificam grande parte do atendimento às crianças de zero a seis anos:

[...] professores com formação geral e especializada deficiente; condições de trabalho precárias; improvisação por parte da gestão das redes municipais, principais responsáveis pela educação infantil; extrema segmentação do sistema; prédios, equipamentos e materiais insuficientes, inadequados ou mal aproveitados; os fatores são muitos (CAMPOS, 2012, p. 19).

Porém, na opinião de Campos (2012), a maior necessidade na superação desse vácuo no qual a Pedagogia da Infância ainda se encontra é a definição de "propostas curriculares claras, aceitas e conhecidas de todas as pessoas que atuam nas instituições" (p. 19). A autora critica a necessidade de que em nome de uma autonomia as equipes pedagógicas, professores e demais educadores "sem a formação e as referências necessárias", precisem 
"reinventar uma pedagogia a partir do zero", o que por fim acaba por favorecer "a reprodução daquela mesma pedagogia que se desejava superar" (p. 19). Nesse sentido, Campos (2012) apoia a ideia de que é necessário ir além das declarações de princípios, produzindo modos de fazer essa pedagogia. E que, para isso, é primordial considerar o contexto no qual estamos inseridos para não ficarmos alheios à "dimensão política que todas as opções pedagógicas sempre trazem, de forma mais ou menos explícita" (p. 19). A autora finaliza sua posição quanto ao estabelecimento de uma Pedagogia da Infância no Brasil destacando o fato de que:

\begin{abstract}
Essa dimensão política (e ética) que toda proposta pedagógica carrega consigo está presente não só na valorização da escuta e da participação da criança, mas também se expressa no compromisso com valores sociais como a igualdade, a justiça, a liberdade, a solidariedade. A aproximação da pedagogia com a criança não pode significar, nessa perspectiva, o abandono da educação como projeto emancipador (CAMPOS, 2012, p. 20).
\end{abstract}

Nossa posição, ao lado da perspectiva das Pedagogias da Infância, acredita que a centralidade da/na criança não significa o abandono da educação, tampouco um desmerecimento da construção de aprendizagens na etapa da Educação Infantil. A pedagoga portuguesa Oliveira-Formosinho (2007) traz contribuições importantes para esse debate, apresentando semelhante preocupação quanto às dificuldades de a Pedagogia da Infância ultrapassar a dimensão do palavreado e "penetrar a carapaça burocrática que protege a pedagogia transmissiva tradicional" (OLIVEIRA-FORMOSINHO, 2007, p. 13).

Oliveira-Formosinho (2007) afirma que transpor essa barreira colocada entre os discursos e as práticas é da ordem do compromisso político, um dever cívico. No entanto, a autora portuguesa acredita que já dispomos de memória histórica para que essa transformação nas práticas educativas aconteça, uma vez que há "uma herança rica e diversificada de pensar a criança como ser participante, e não como um ser em espera de participação" (p. 13).

Nessa busca por estabelecer pedagogias que possibilitem à criança a experiência da infância e que estejam comprometidas com a ideia da educação como projeto de emancipação, Oliveira-Formosinho (2007) destaca que uma pedagogia — de qualquer ordem - opera sempre em um complexo âmbito que envolve ações (aquilo que se faz), teorias (aquilo que se estuda) e crenças (aquilo no qual se acredita). A autora afirma que, ao ter como lócus a práxis, a pedagogia se torna ainda mais complexa pois considera essas três premissas - ação, teoria e crenças — de modo articulado.

Nesse sentido, Oliveira-Formosinho (2007) defende a ideia de que o estabelecimento de uma pedagogia da infância que esteja comprometida com a educação como projeto de 
emancipação dos sujeitos está no desenvolvimento de uma pedagogia participativa. Para a autora:

\begin{abstract}
Uma pedagogia centrada na práxis de participação procura responder à complexidade da sociedade e das comunidades, do conhecimento, das crianças e de suas famílias, com um processo interativo de diálogo e confronto entre crenças e saberes, entre saberes e práticas, entre práticas e crenças, entre esses pólos em interação e os contextos envolventes (p. 15).
\end{abstract}

Sob essa ótica, uma pedagogia participativa se constrói na desconstrução de uma pedagogia transmissiva. No conhecimento das características de uma e de outra é que se faz possível reconhecer e rever ações, reposicionando nossas crenças. Para isso, é importante reconhecer aspectos que constituem as pedagogias e como eles diferem entre as pedagogias participativas e as pedagogias transmissivas. O que se encontra no centro do processo educativo nas pedagogias transmissivas é a preocupação com os conhecimentos que se quer difundir, definindo o modo e o tempo em que essa transmissão vai se dar. Dessa forma, elas agem neutralizando todas as demais dimensões que contextualizam as relações de aprendizagem e ignorando a complexidade dessas relações. A previsibilidade e determinada segurança no desenvolvimento dessas pedagogias fazem com que elas ainda persistam nas práticas da educação de bebês e crianças de zero a seis anos de idade, resistindo às abordagens participativas, mesmo quando os discursos dessas e algumas experiências pontuais e localizadas já estejam presentes em nosso meio pedagógico (OLIVEIRAFORMOSINHO, 2007).

Por outro lado, as pedagogias participativas buscam estruturar as experiências dos sujeitos, construindo aprendizagens que deem sentido e significado para essas experiências. Trata-se da complexidade de uma pedagogia centrada nos processos, com alto nível de interação ocorrendo em diversos âmbitos. Nas pedagogias participativas, os conhecimentos produzidos pelas crianças dialogam com aqueles produzidos pela humanidade e é fundamental a presença de um professor que escuta, observa, formula perguntas e investiga.

Certamente, para romper com as pedagogias transmissivas e sustentar uma pedagogia participativa, não basta reconhecermos as características de uma e apontarmos as dificuldades na implementação de outra. É necessário, portanto, estarmos atentos ao fato de que - como afirma Oliveira-Formosinho apoiada em Paulo Freire — "em pedagogia a ruptura não é um mero exercício de desocultação, mas sim um compromisso com a reconstrução e com a esperança" (2007, p. 18).

A partir dessas premissas, buscou-se na seção abaixo apresentar as ideias sobre educação e democracia, de Paulo Freire, que podem nos subsidiar com possibilidades de 
avanço para o desenvolvimento das Pedagogias da Infância também como projeto emancipador, caminhando mais um passo em sua consolidação.

\section{Educação e democracia em Freire: possibilidades de sustentação às Pedagogias da Infância}

É por esta ética inseparável da prática educativa, não importa se trabalhamos com crianças, jovens ou com adultos, que devemos lutar. E a melhor maneira de por ela lutar é vivê-la em nossa prática (FREIRE, 1996, p. 16).

A presença de Paulo Freire (1996; 2014; 2019; 2020a; 2020b) nesta subseção — ainda que o autor não tenha escrito suas ideias pensando nas crianças bem pequenas - ajuda a compreender e a encontrar caminhos para a solução de possíveis contradições que possam existir entre as Pedagogias da Infância e o desenvolvimento de uma educação comprometida com a aprendizagem dos sujeitos e com a transformação da sociedade.

A primeira delas está ligada à preocupação apresentada por Maria Malta Campos a respeito da centralidade na/da criança no desenvolvimento das práticas educativas em detrimento do compromisso com os valores sociais, políticos e éticos que a educação carrega, ou seja, a preocupação de que a aproximação da pedagogia com a criança não significa, nessa perspectiva, o abandono da educação como projeto emancipador (CAMPOS, 2012). O segundo aspecto diz respeito ao compromisso da escola com a aprendizagem das crianças e de como essa relação ensino-aprendizagem pode ser compreendida a partir de um reposicionamento nos papéis historicamente desenvolvidos pelas crianças e adultos na Educação Infantil.

Tais problematizações são feitas a partir dos pensamentos de Freire e das contribuições filosóficas e pedagógicas que o autor trouxe para a educação, especialmente no que se refere a processos educativos comprometidos com a emancipação dos sujeitos e com a transformação da realidade.

As preocupações apresentadas por Campos (2012), bem como as críticas direcionadas às Pedagogias da Infância (ARCE, 2004; STEMMER, 2006; ARCE E MARTINS, 2007), estão presentes desde o nascimento desse conceito no Brasil e permanecem bastante presentes no contexto atual. Nas disputas discursivas pelo que deve vigorar nas práticas educativas desenvolvidas com as crianças de zero a seis anos de idade, e especialmente no que se refere à produção de currículos, ainda estamos a pendular entre duas perspectivas: 
precisam para esse momento da vida na livre-exploração, de outro, aqueles que defendem uma visão de instrução na Educação Infantil e a antecipação dos conteúdos do Ensino Fundamental (FOCHI, 2020, p. 53).

Para Freire, a educação é, antes de tudo, um ato político de participação, um processo pelo qual os seres humanos podem "partirem do que são para o que querem ser" (ROMÃO, 2018, p. 159), ou seja, o processo de "ser mais". Freire (1996) sustentava que o perceber-se inacabado foi o que permitiu e impulsionou, aos homens e mulheres, a educabilidade e o entendimento do processo de aprendizado como um percurso permanente (FREIRE, 1996).

Como meios de educar, o filósofo identificava duas correntes: a educação bancária, (que podemos relacionar com as pedagogias transmissão) que desumaniza as pessoas - a partir do pressuposto de que não possuem conhecimentos, desejos e liberdade - fazendo uso da opressão para atingir seus objetivos; e a educação libertadora, que busca promover mais consciência, mais liberdade e mais humanização, promovendo a ampliação da participação de todos. Tal corrente solicita fundar uma circunstância na qual a participação, o diálogo e a autonomia sejam os componentes invariáveis da práxis educativa e, na perspectiva freiriana, essa somente se desenvolve em um ambiente verdadeiramente democrático.

A respeito da democracia, para Freire (2019), antes de se tratar de um método político, é uma condição humana de construção histórico-social, orientada na e para a humanização dos sujeitos por meio da educação e da política. Desse modo, é uma ação e uma conquista coletivas, consequência do diálogo, do respeito aos saberes e do poder na tomada de decisões por todos aqueles que comungam do processo de humanização do ser humano (biológico), como resultado da sua vocação para ser sujeito (ser social). No ideário freiriano, democracia é aquilo que propicia e engendra uma forma de vida e convivência interpessoal na qual se configuram relações intersubjetivas que constituem as práticas políticas e pedagógicas, refutando ações de autoritarismo que negam a liberdade de escolha.

Nesse sentido, a construção da democracia precisa de pessoas capazes de solucionar seus próprios problemas sociais. Para tanto, é preciso que o desenvolvimento dessas capacidades aconteça na e com a participação ativa e livre em uma vida democrática. É inerente à pedagogia freiriana a indissociabilidade entre democracia e educação e é possível afirmar que, para Freire, somente uma educação participativa - que se pretende problematizadora e dialógica - pode estabelecer uma educação verdadeiramente democrática, capaz de concretizar a vocação ontológica humana de "ser mais" (FREIRE, 2019). 
Esses indicativos, são profícuos para sustentar pedagogias da infância que têm com um de seus princípios a garantia da participação das crianças em seus processos educativos desde muito pequenas. A busca pela participação de todos nos processos de aprendizagem foi uma das grandes defesas de Paulo Freire, bem como a crença na escola pública como o lócus privilegiado desses processos. A defesa da escola pública como a escola de todos foi a marca da gestão de Freire como Secretário da Educação em São Paulo e ele explicitou sua concepção dessa "escola cidadã" em entrevista para a TV Educativa do Rio de Janeiro:

\begin{abstract}
A Escola Cidadã é aquela que se assume como um centro de direitos e de deveres. $\mathrm{O}$ que a caracteriza é a formação para a cidadania. A Escola Cidadã, então, é a escola que viabiliza a cidadania de quem está nela e de quem vem a ela. Ela não pode ser uma escola cidadã em si e para si. Ela é cidadã na medida mesma em que se exercita na construção da cidadania de quem usa o seu espaço. A Escola Cidadã é uma escola coerente com a liberdade. É coerente com o seu discurso formador, libertador. É toda escola que, brigando para ser ela mesma, luta para que os educandos-educadores também sejam eles mesmos. E como ninguém pode ser só, a Escola Cidadã é uma escola de comunidade, de companheirismo. É uma escola de produção comum do saber e da liberdade. É uma escola que vive a experiência tensa da democracia (FREIRE, 1997).
\end{abstract}

Freire também acreditava na liberdade e na democracia como condições para que as pessoas pudessem realizar escolhas e exercer suas condições como seres atuantes. $\mathrm{O}$ autor não advogou por uma liberdade como realização de todos os desejos, sem qualquer limite. Ao contrário, ele fundamenta sua posição em dois argumentos: o primeiro diz respeito ao fato de que liberdade que não considera outras vontades, que se opõe às vontades alheias, é uma "vontade ilícita, dos 'donos do mundo' que, egoístas, só se veem a si mesmos" (FREIRE, 2014, p.34). Em outras palavras, Freire afirmava que a liberdade não estava acima de qualquer limite; ao contrário, assegurava que "a liberdade sem limite é tão negada quanto a liberdade asfixiada", e que essa liberdade que assume limites é amadurecida "no confronto com outras liberdades, na defesa dos seus direitos em face da autoridade" (FREIRE, 1996, p. 105). A esse respeito, Freire destacava ainda que os educadores — pais, professores não podem se furtar de oferecer a orientação necessária para que os filhos ou educandos possam fazer escolhas conscientes dentro de suas liberdades. No entanto, assumia que era preferível "reforçar o direito que [o indivíduo] tem a liberdade de decidir, a seguir a decisão dos pais" apostando, assim, na ideia de que "é decidindo que se aprende a decidir" (FREIRE, 1996, p. 106).

O segundo argumento que o filósofo utiliza para falar dessa liberdade ponderada, não como a ideia de ter todas as suas vontades atendidas, mas naquela de ser atuante, era o fato de que nem sempre nossas vontades - nossos desejos - são realmente nossas. Freire denunciava já o sedutor interesse, por parte dos oprimidos, pela ideia que disseminam - e 
pelas posses que têm — os opressores. Assim, "participar destes padrões constitui uma incontida aspiração. Na sua alienação querem, a todo custo, parecer com o opressor. Imitálo. Segui-lo" (FREIRE, 2020, p.68).

Considerando esses dois argumentos acima apresentados, compreende-se a defesa de Paulo Freire por uma educação libertadora, que atue "em dois campos simultaneamente: no âmbito da interioridade humana (consciência e desejo); e no âmbito sociopolítico uma vez que "[...] a liberdade é uma conquista que se alcança na medida em que se luta pela libertação de si, do outro e do mundo" (SUNG, 2018, p. 290). A educação para Freire, então, trafegava entre a esfera do individual (consciência e desejo) e a esfera do coletivo (sociopolítico). Desse modo, pode-se dizer que a aprendizagem tem estes dois campos de atuação: percursos individuais e percursos coletivos, ou seja, transita também entre o indivíduo e a sociedade.

Além disso, para Freire, o ato de aprender relaciona-se com a compreensão do mundo em sua totalidade, nas diferentes dimensões: o estético, o científico, o popular e o senso comum. "O saber popular, o senso comum, são partes integrantes e indissociáveis do aprendizado do saber da ciência e da técnica" (JUSTO E ADAMS, 2018, p. 53). O ato de aprender, nessa perspectiva, considera o saber do educando, o entendendo como sujeito ativo no processo de conhecer. É um ato dialógico que implica uma atividade dinâmica entre pensamento, linguagem e realidade, e não aparta o fazer do pensar. Assim, o saber tem um caráter transitório, marcado pelo movimento dos processos históricos que forjam os seres humanos, nas suas capacidades de produzirem-se e de transformarem a sua condição de existência (JUSTO E ADAMS, 2018).

Freire teve algumas de suas ideias relativas ao processo de ensino e aprendizagem mal interpretadas. A principal delas talvez tenha sido, diante do modo como entendia a relação ensino-aprendizagem, a de que o professor não ensina e sobre isso ele afirmava de forma clara: "O professor deve ensinar. É preciso fazê-lo. Só que ensinar não é transmitir conhecimento" (FREIRE, 1993, p. 118). Na relação ensino e aprendizagem, Freire defendia a ideia de que aprender não era apenas recepção de conteúdo, pois não era movimentação de saberes de quem detém um conceito para outro que não o possui; ou seja, ensinar não é transferência de conhecimento e sim criação de "possibilidades para a sua produção" (FREIRE, 1996, p. 25). Assim, afirma que ensinar e aprender fazem parte do processo de aprender, no qual "educadores e educandos, mediatizados pelo mundo, são sujeitos mutuamente implicados" (FREITAS, 2018, p. 185).

$\mathrm{Na}$ perspectiva freiriana, os processos de ensino e aprendizagem, tal como para Vygotsky, se dão no campo da interação, nos quais "quem ensina aprende ao ensinar e quem aprende ensina ao aprender" (FREIRE, 1996, p. 25). Por esse motivo tais processos se 
desenvolvem a partir dos contextos reais dos educandos e entendendo suas experiências cotidianas como oportunidade de elaboração de conhecimento (FREIRE, 1993).

O autor reafirma a ideia de que na educação libertadora não se diminui o valor dos conteúdos tampouco a função dos professores no processo de conhecer, ao explanar a importância que esses exercem na promoção da curiosidade ingênua para a curiosidade epistemológica. Segundo Freire, a curiosidade ingênua — da qual resulta um certo saber ainda que desprovido de rigorosidade - é uma curiosidade "desarmada" como daqueles que olham "as nuvens que se movem rápidas, alongando-se umas nas outras, no fundo azul do céu" (FREIRE, 2020b, p.136). Freire fala do valor e do respeito a esse saber feito da experiência, como também da necessária "promoção" à curiosidade epistemológica: aquela que - não abandonando a imaginação criadora - tomando distância do objeto de conhecimento aproxima-se "para conhecê-lo e dele falar prudentemente (FREIRE, 2020b, p. 136). Segundo o autor:

Na verdade, a curiosidade ingênua que, "desarmada", está associada ao saber do senso comum, é a mesma curiosidade que, criticizando-se, aproximando-se de forma cada vez mais metodicamente rigorosa do objeto cognoscível, se torna curiosidade epistemológica. Muda de qualidade, mas não de essência (FREIRE, 1996, p. 31).

Esse processo de mudança na qualidade da curiosidade ingênua para a curiosidade epistemológica não se dá espontaneamente, mas demanda o compromisso da escola e dos professores com a aprendizagem e com o processo de aprendizagem dos educandos. Esse processo deve respeitar e considerar os saberes que esses educandos portam à escola, tanto quanto deve articular "a razão de ser de alguns desses saberes em relação com o ensino de conteúdos", percebendo a "intimidade entre os saberes curriculares fundamentais aos alunos e a experiência social que eles têm como indivíduos" (FREIRE, 1996, p. 30).

Essa construção argumentativa do autor também é valiosa às Pedagogias da Infância que, em consonância com as DCNEls, concebe o currículo na Educação Infantil como um conjunto de práticas que articulam os saberes e interesses das crianças com o patrimônio sistematizado pela sociedade (BRASIL, 2009). Nesse sentido, entendemos que a pedagogia freiriana, que consiste em uma educação conectada ao cotidiano dos estudantes e às experiências que eles têm, pautada no diálogo e no reconhecimento dos sujeitos como aprendizes ativos, se relaciona às Pedagogias da Infância ao: (i) afirmar que ensinar não é transferir conhecimento, e sim criar condições para a sua produção; (ii) estabelecer intimidade entre os saberes curriculares fundamentais aos alunos e a experiência social que esses têm como indivíduos; (iii) destacar que transformar a experiência educativa em treinamento 
técnico é amesquinhar o que há de fundamentalmente humano no exercício educativo: o seu caráter formador; (iv) compreender a reflexão crítica sobre a prática como exigência da relação teoria-prática sem a qual a teoria pode virar blábláblá e a prática ativismo; (v) explicitar que a melhor forma de falar sobre direitos com os alunos é vivê-los na cotidianidade da escola; e (vi) entender que o professor que está respeitosamente presente à experiência formadora do educando afirma os princípios éticos da relação educativa (FREIRE, 1996).

A livre interpretação que fazemos ao estabelecer relações entre a pedagogia freiriana e as Pedagogias da Infância emerge por acreditarmos, tal como Freire (2020a), que uma pedagogia precisa ser elaborada com os sujeitos e não para eles, e ganha força ao perceber que os princípios filosóficos da Educação de Paulo Freire estão em franco diálogo com os princípios, valores e crenças das Pedagogias da Infância.

Colocadas as ideias a respeito de educação e democracia em Freire, bem como as relações que estabelecemos entre os ideais e pressupostos dos autores e Pedagogias da Infância, retomam-se agora os três aspectos apresentados no início deste texto, sintetizando argumentos que podem esclarecer os equívocos que por vezes aparecem quando se ataca — ou mesmo quando se defende - o desenvolvimento de uma Pedagogia da Infância no âmbito das pedagogias participativas.

Em relação ao dilema entre onde deve estar posicionado o centro da ação educativa - na criança ou no currículo -, utilizando-se das afirmações de Freire já expostas anteriormente neste texto, acredita-se que é possível assumir a premissa de que, para o filósofo, o eixo central da ação educativa está nas relações estabelecidas entre os sujeitos (adultos e crianças) e os objetos de conhecimento e que na Educação Infantil essas relações se dão fundamentalmente nas brincadeiras e interações que se estabelecem no âmbito da escola.

Desse modo, as Pedagogias da Infância compreendem que não há oposição entre criança e currículo. Encontra-se em Freire a validação dessa premissa ao afirmar categoricamente que "O professor deve ensinar. É preciso fazê-lo. Só que ensinar não é transferir conhecimento" (FREIRE, 1993, p. 118). Tais premissas freirianas evidenciam que: existe ensino (e, portanto, conhecimentos); o professor tem por tarefa ensinar (existe atuação docente intencional); e aprender exige do aprendiz uma atitude ativa, pois a construção, ou produção do conhecimento, se dará não por transferência, mas por relação entre os sujeitos mediatizados pelo mundo. Com isso, Freire nos leva a compreender o equívoco de pensar que ou se está a favor do conhecimento (currículo), ou a favor do educando. O autor faz a provocação também de reposicionar a função docente quando constrói a ideia de que "o papel 
do(a) educador(a) e a experiência do(a) educando(a) na relação com o contexto articulam-se dialeticamente" (ADAMS, 2018, p. 306).

Quanto ao compromisso da escola com a ampliação das aprendizagens das crianças, recuperamos algumas ideias quanto ao objetivo da educação e como essa se organiza em ambiente institucionalizado para Freire. Para o autor, a educação democrática se desenvolve em um ambiente de vida coletiva no qual cada membro desse coletivo se integra de modo livre, ativo e responsável nas diferentes atividades que lá ocorrem. Sabemos que, tratandose de Educação Infantil, essa dinâmica deve ser estabelecida inicialmente pelos adultos que ocupam o lugar de pensar os princípios da instituição, vivendo eles também esse ambiente como professores e demais trabalhadores em educação.

Paulo Freire abordava o tema sobre a atmosfera do ambiente educativo afirmando que "ensinar exige respeito à autonomia do ser do educando" seja ele "criança, jovem ou adulto" (FREIRE, 1996, p. 59). Esse respeito à autonomia e à dignidade o qual Freire aborda é um "imperativo ético e não um favor que podemos ou não conceder uns aos outros" (FREIRE, 1996, p. 59) e que essa condição de respeito à autonomia do educando não exime o professor de estar "presente à experiência formadora do educando" (FREIRE, 1996, p. 60).

Com isso, é possível afirmar que tanto as Pedagogias da Infância quanto a pedagogia freiriana defendem a ideia de que o compromisso da escola com a educação dos educandos é tarefa dos professores, que, como profissionais da aprendizagem, devem garantir, por meio das suas habilidades e competências técnicas, que os saberes das crianças, dos jovens e dos adultos ampliem-se nas jornadas que passam nas escolas. Por fim, depreende-se que a proposição aqui anunciada, de um diálogo e articulação do pensamento freiriano às Pedagogias da Infância, além de contribuir para a sustentação dessas últimas, também anuncia um fértil caminho em direção a um projeto educativo democrático para a Educação Infantil.

\section{Considerações finais}

Durante a realização deste trabalho, buscou-se articular as Pedagogias da Infância ao pensamento freiriano. Considerou-se que ambas as propostas educativas advogam a favor de uma escola que emancipe os sujeitos e creem nessa emancipação a partir do conhecimento. Esse encontro é profícuo para sustentar a ideia de que os conhecimentos novos se produzem a partir daquilo que já se sabe, e que é preciso permitir espaço à curiosidade e à aptidão dos humanos para que a escola possa cumprir seu papel de ampliação dos saberes e de compromisso com a emancipação dos sujeitos educandos. 
Acredita-se que esse diálogo possibilita reconhecer a sinergia entre os ideais de respeito à individualidade e as normas de atendimento às necessidades sociais, avançando nas críticas que têm sido fortemente tecidas às Pedagogias da Infância desde sua imersão no meio acadêmico.

A respeito da provocação de que há a impossibilidade de desenvolver uma ação pedagógica intencional que esteja ancorada nos pressupostos das Pedagogias da Infância sem perder de vista normativas curriculares, acredita-se que, considerando as ideias aqui apresentadas, especialmente a da não oposição entre conhecimentos programados e conhecimentos dos sujeitos, é possível inferir que não existe contradição entre uma proposição curricular e as Pedagogias da Infância; tampouco existe, nesse sentido, necessidade de fazer escolhas entre a educação como projeto social-democrático e a valorização dos saberes e experiências das crianças.

Por fim, partindo da compreensão de que o desenvolvimento de Pedagogias da Infância não é incompatível com o desenvolvimento de um currículo - de conteúdos e saberes historicamente construídos - é necessário destacar que tais pedagogias podem ser instituídas na medida em que os direitos das crianças forem afirmados como aspecto essencial na docência. Docência essa que, compreendendo a horizontalidade das relações entre crianças, conhecimentos e adultos, reconhece o desenvolvimento da sua função, não a desmerecendo. A educação como projeto de emancipação não precisa significar subordinação ao currículo, bem como o reconhecimento do valor da experiência da criança não significa espontaneísmo nas práticas educativas.

\section{Referências}

ADAMS, Telmo. Mediação. In: STRECK, Danilo R.; REDIN, Euclides; ZITKOSKI, Jaime José. Dicionário Paulo Freire. Belo Horizonte: Autêntica Editora, 2018.

ARROYO, Miguel G. Currículo, território em disputa. Petrópolis: Vozes, 2013.

ARCE, Alessandra. Pedagogia da infância ou fetichismo da infância? In: DUARTE, Newton (Org.). Crítica ao fetichismo da individualidade. Campinas, SP: Autores Associados, 2004. p. 145-168.

ARCE, Alessandra; MARTINS, Lígia Márcia (orgs.). Quem tem Medo de Ensinar na Educação Infantil? Em defesa do ato de ensinar. 4. ed. Campinas: Alínea, 2007.

BARBOSA, Maria Carmen Silveira. Pedagogia da infância. In:OLIVEIRA, D.A.; DUARTE, A.M.C.; VIEIRA, L.M.F. DICIONÁRIO: trabalho, profissão e condição docente. Belo Horizonte: UFMG/Faculdade de Educação, 2010. CDROM 
BARBOSA, Maria Carmen Silveira. Culturas infantis: contribuições e reflexões. Revista. Diálogo Educ., Curitiba, v. 14, n. 43, p. 645-667, set./dez. 2014

BRASIL. Resolução n. 5, de 17 de dezembro de 2009. Fixa as Diretrizes Curriculares Nacionais para a Educação Infantil. Conselho Nacional de Educação/Câmara de Educação Básica. Brasília: CNE/CEB, 2009

CAMPOS, Maria Malta. Infância como construção social: contribuições do campo. In: VAZ, Alexandre Fernandez; MOMM, Caroline Machado (Org.). Educação Infantil e sociedade: questões contemporâneas. Nova Petrópolis: Nova Harmonia, 2012. p. 11-20.

FARIA, Ana Lúcia G. Educação pré-escolar e cultura: para uma pedagogia da educação infantil. Campinas, SP: Editora da Unicamp; São Paulo: Cortez, 1993.

FREIRE, Paulo. Professora sim, tia não: cartas a quem ousa ensinar. São Paulo: Olho D’Água, 1993.

FREIRE, Paulo. Pedagogia da autonomia: saberes necessários à prática educativa. São Paulo: Paz e Terra, 1996.

FREIRE, Paulo. Pedagogia da indignação: cartas pedagógicas e outros escritos. São Paulo: Paz e Terra, 2014.

FREIRE, Paulo. Educação como prática para a liberdade. 46. ed. São Paulo: Paz e Terra, 2019.

FREIRE, Paulo. Pedagogia do oprimido. 73. ed. Rio de Janeiro/São Paulo: Paz e Terra, 2020a.

FREIRE, Paulo. Política e Educação. 5. ed. Rio de Janeiro/São Paulo: Paz e Terra, $2020 b$.

FREITAS, Ana Lúcia Souza de. Ensinar e aprender. In: STRECK, Danilo R.; REDIN, Euclides; ZITKOSKI, Jaime José. Dicionário Paulo Freire. Belo Horizonte: Autêntica Editora, 2018.

JUSTO, Hirã Soares e ADAMS, Telmo. Aprender. In: STRECK, Danilo R.; REDIN, Euclides; ZITKOSKI, Jaime José. Dicionário Paulo Freire. Belo Horizonte: Autêntica Editora, 2018.

MACINAI, Emiliano. L'infanzia e suoi diritti - sentieri storici, scenari globali e emergenze educative. Pisa: Edizioni ETS, 2006.

MACINAI, Emiliano. Pedagogia e diritti dei bambini - uno sguardo storico. Roma: Carocci Editore, 2013.

OLIVEIRA-FORMOSINHO, Júlia; KISHIMOTO, Tizuko Morchida; PINAZZA, Mônica Apezzato (Orgs.). Pedagogia(s) da infância: dialogando com o passado: construindo o futuro. Porto Alegre: Artmed, 2007.

OLIVEIRA-FORMOSINHO, Júlia. Pedagogia(s) da infância: reconstruindo uma práxis de participação. In: OLIVEIRA-FORMOSINHO, Júlia; KISHIMOTO, Tizuko Morchida; PINAZZA, Mônica Appezzato (Orgs.). Pedagogia(s) da infância: dialogando com o passado:

construindo o futuro. Porto Alegre: Artmed, 2007. 
ROCHA, Eloisa Acires Candal. A pesquisa em Educação Infantil no Brasil: trajetória recente e perspectivas de consolidação de uma pedagogia. 1999. Tese (Doutorado em Educação). UNICAMP, Campinas, 1999. 291f.

ROCHA, Eloisa, Acires Candal.Sem título. [Entrevista concedida a] Luciana Pandini Simiano. Poiésis, Tubarão. V. 7, n. 11, Jan/Jun, 2013.

ROCHA, Eloisa Acires Candal; BUSS-SIMÃO, Márcia; LESSA, Juliana Schumacker. Pedagogia da Infância: interlocuções disciplinares na pesquisa em Educação. Da Investigação às práticas, n.6 (1), CIED - Centro Interdisciplinar de Estudos Educacionais, Mar. 2016. p. $31-49$.

ROMÃO, José Eustáquio. Educação. In: STRECK, Danilo R.; REDIN, Euclides; ZITKOSKI, Jaime José. Dicionário Paulo Freire. Belo Horizonte: Autêntica Editora, 2018.

STEMMER, Márcia Regina Goulart da Silva. Educação infantil e pós-modernismo: a abordagem de Reggio Emilia. 2006. Tese (Doutorado em Educação). UFSC, Florianópolis/SC, 2006. 182f.

SUNG, Jung Mo. Liberdade. In: STRECK, Danilo R.; REDIN, Euclides; ZITKOSKI, Jaime José. Dicionário Paulo Freire. Belo Horizonte: Autêntica Editora, 2018.

Recebido em: 10/08/2021

Aceito em: 29/09/2021 